\title{
MULTIVARIATE METHODS AS AN AID IN IDENTIFYING POA AMPLA $\times$ P. PRATENSIS HYBRIDS FROM MATERNAL-TYPE OFFSPRING
}

\author{
CYNTHIA J. WILLIAMSON and R. J. KILLICK \\ Scottish Plant Breeding Station, Pentlandfield, Roslin, Midlothian EH25 9RF
}

Received 18.v.78

\begin{abstract}
SUMmary
An objective screening procedure was needed which would enable separation of $F_{1}$ hybrids between $P o a$ ampla and $P$. pratensis for use in a plant breeding programme from maternal-type offspring. Data from a cloned plant field trial were used in canonical analysis of discriminance, principal components analysis and principal co-ordinate analysis; a measure of Euclidean distance was also computed.

The relationship between hybrid, maternal and parent biotypes appeared remarkably consistent from the three forms of analysis over the first two axes of variation and to a lesser extent on the third axis. Euclidean distances were very highly correlated with the positions of clones on the first axis of variation in each of the analyses. Maternal clones were clearly separated from hybrids by each of these four methods and this distinction was supported by a more subjective visual assessment made in the field.
\end{abstract}

\section{INTRODUCTION}

InTERSPEGifia hybrids were produced between Poa ampla Merr. and $P$. pratensis L. (sensu lato) in a breeding programme with the objective of introgressing characteristic early season growth from $P$. ampla into $P$. pratensis. Both species are facultative apomicts; apomictic seed production has been shown to be aposporous and pseudogamous (Åkerberg, 1939, 1942 and Müntzing, 1940). The biotypes used as parents in the breeding programme all yielded a very high proportion of apomictic seed when grown at the Scottish Plant Breeding Station.

Most $F_{1}$ hybrids between these species can be distinguished from maternal (apomictically produced) offspring by their morphological characters. Visual assessments on seedlings and in the field have been used to screen similar material for the presence of hybrids (Clausen, Keck and Hiesey, 1944 and 1945). However it can be difficult to separate hybrids which are phenotypically similar to the maternal types on the basis only of visual assessments which are necessarily subjective.

Grun (1954) was able to relate some morphological characters to somatic chromosome number in interspecific hybrids of Poa. Chromosome counts were not found to be sufficiently reliable in Pentlandfield material to help in identifying hybrids due to the frequent occurrence of aneusomaty (Williamson, 1976), a characteristic also noted in $P$. pratensis by Speckman and van Dijk (1972). There were no marker genes available in the material to aid in screening for hybrids. Almgård (1969) successfully used electrophoretic methods to distinguish hybrid from maternal plants within a partially apomictic family of $P$. pratensis. Spoor and Hay (1978) were able 
to separate hybrids from $P$. ampla and $P$. pratensis parental lines using esterase and peroxidase isozymes in material supplied by the Scottish Plant Breeding Station.

Multivariate statistical methods should give an objective assessment of the relationship of putative hybrids to their parents, and are easily applicable to a large number of individuals which need to be screened in a plant breeding programme. Krzanowski (1972) reviews several of the standard techniques in multivariate analysis. In the present paper four multivariate methods are compared in an attempt to find the most appropriate procedure to give a clear separation of maternal from hybrid offspring.

\section{Materials AND methods}

Nine biotypes of $P$. pratensis were pair-crossed with two biotypes of $P$. ampla but not all combinations were available (table 1). Seed was harvested only from $P$. ampla. It was germinated in a glasshouse and after several weeks seedlings which showed any apparent deviation from the $P$. ampla habit were selected for further study. These seedlings together with all $P$. pratensis parent biotypes and one of the $P$. ampla parent biotypes were vegetatively cloned. The second biotype of $P$. ampla was not available for cloning. Ten ramets of each clone were planted at $600 \times 600 \mathrm{~mm}$ spacing in randomised blocks.

The following data were recorded on all ramets:

EE Ear emergence (half weeks)--date on which third panicle appeared above the ligule of flag leaf.

\section{FLL Flag leaf length (mm)}

FLB Flag leaf breadth (mm) $\mathrm{PH}$ Plant height $(\mathrm{cm})$

Pan, no. Number of panicles

PD Plant diameter $(\mathrm{cm})$

SG Spring growth (categories I to 3)
- lamina length measured on a representative flowering tiller.

-measured half way along lamina.

-measured from ground to top of second longest panicle.

\section{-greatest spread}

- category I, most leaves dead; category 3 , most leaves green.

Data were tested for normality using a programme which gave a measure of skewness and kurtosis (Sokal and Rohlf, 1969). Transformations were carried out in an attempt to minimise the degree of skewness and kurtosis. Homogeneity of within-clone dispersion matrices was tested using the method given by Seal (1964).

Canonical analysis and principal components analysis are R-techniques based on variate by variate (SSP) matrices and are both standard mathematical procedures with the requirement that data should be multivariate normally distributed (Hope, 1968). Principal co-ordinate analysis was developed as a method in numerical taxonomy; it is a $Q$-technique using an association matrix formed from the comparison between all pairs of individuals (Gower, 1966), and therefore does not have a formal requirement for multivariate normality. A canonical analysis of discriminance was performed based on the algorithm given by Seal (loc. cit.) and using a 
TABLE 1

Clone means for seven variates and distance $(d)$ of each clone from $\mathrm{P}$. ampla and from its pollen parent

\begin{tabular}{|c|c|c|c|c|c|c|c|c|c|c|c|}
\hline $\begin{array}{c}\text { Clone } \\
\text { index } \\
\text { no. }\end{array}$ & $\begin{array}{l}\text { No. } \\
\text { ramets }\end{array}$ & $\mathrm{EE}$ & $\begin{array}{l}\text { FLL } \\
\mathrm{mm}\end{array}$ & $\begin{array}{l}\text { FLB } \\
\mathrm{mm}\end{array}$ & $\begin{array}{l}\mathrm{PH} \\
\mathrm{cm}\end{array}$ & $\begin{array}{c}\text { Pan } \\
\text { no. }\end{array}$ & $\begin{array}{l}\mathrm{PD} \\
\mathrm{cm}\end{array}$ & $\mathrm{SG}$ & $\begin{array}{c}d \\
\text { P. ampla }\end{array}$ & $\begin{array}{c}d \\
\text { pollen } \\
\text { parent }\end{array}$ & $\begin{array}{c}\text { Hybrid } \\
\text { or } \\
\text { maternal }\end{array}$ \\
\hline 1 & 10 & $1 \cdot 10$ & $94 \cdot 00$ & $3 \cdot 00$ & $65 \cdot 30$ & $13 \cdot 20$ & $8 \cdot 70$ & $2 \cdot 20$ & 0 & - & - \\
\hline 2 & 10 & $4 \cdot 90$ & $48 \cdot 90$ & $5 \cdot 00$ & $51 \cdot 00$ & $21 \cdot 30$ & $50 \cdot 90$ & $1 \cdot 60$ & 909 & 0 & - \\
\hline 3 & 10 & $1 \cdot 20$ & $114 \cdot 30$ & 3.90 & $75 \cdot 20$ & $21 \cdot 00$ & $9 \cdot 60$ & $2 \cdot 90$ & 177 & 922 & $\mathbf{M}$ \\
\hline 4 & 9 & $4 \cdot 00$ & $71 \cdot 33$ & $4 \cdot 22$ & $71 \cdot 78$ & 18.89 & $24-00$ & $1 \cdot 78$ & 529 & 628 & $\mathbf{H}$ \\
\hline 5 & 10 & $4 \cdot 80$ & $41 \cdot 20$ & $5 \cdot 00$ & $43 \cdot 80$ & $15 \cdot 50$ & $24 \cdot 90$ & $1 \cdot 10$ & 712 & 0 & - \\
\hline 6 & 9 & $1 \cdot 33$ & $107 \cdot 89$ & $4 \cdot 44$ & 78.56 & $18 \cdot 11$ & $12 \cdot 56$ & $2 \cdot 78$ & 240 & 685 & $\mathbf{M}$ \\
\hline 7 & 9 & $2 \cdot 67$ & $49 \cdot 44$ & $3 \cdot 89$ & $52 \cdot 44$ & $15 \cdot 22$ & $18 \cdot 22$ & $1 \cdot 33$ & 447 & 411 & $\mathrm{H}$ \\
\hline 8 & 10 & $3 \cdot 60$ & $36 \cdot 20$ & $3 \cdot 20$ & $43 \cdot 70$ & $17 \cdot 70$ & $7 \cdot 30$ & $1 \cdot 10$ & 472 & 378 & $\mathrm{H}$ \\
\hline 9 & 10 & $1 \cdot 10$ & $119 \cdot 10$ & $3 \cdot 80$ & $80 \cdot 40$ & $27 \cdot 80$ & $8 \cdot 80$ & $2 \cdot 80$ & 233 & 775 & $\mathbf{M}$ \\
\hline 10 & 10 & $3 \cdot 60$ & $37 \cdot 30$ & $4 \cdot 40$ & $46 \cdot 50$ & 33.90 & $34 \cdot 50$ & $1 \cdot 20$ & 691 & 0 & - \\
\hline 11 & 9 & $1 \cdot 33$ & $111 \cdot 11$ & $4 \cdot 33$ & $79 \cdot 89$ & $15 \cdot 11$ & $11 \cdot 44$ & $2 \cdot 89$ & 244 & 725 & M \\
\hline 12 & 10 & $3 \cdot 60$ & $31 \cdot 00$ & $2 \cdot 90$ & 38.00 & $8 \cdot 40$ & $11 \cdot 90$ & $1 \cdot 30$ & 4.74 & 392 & $\mathbf{H}$ \\
\hline 13 & 10 & $4 \cdot 10$ & $32 \cdot 00$ & $4 \cdot 60$ & $38 \cdot 30$ & $25 \cdot 30$ & $41 \cdot 00$ & $1 \cdot 10$ & 831 & 0 & - \\
\hline 14 & 10 & $3 \cdot 20$ & $38 \cdot 10$ & 3.90 & $47 \cdot 40$ & $23 \cdot 70$ & $19 \cdot 60$ & $1 \cdot 20$ & 524 & 482 & $\mathrm{H}$ \\
\hline 15 & 7 & $1 \cdot 14$ & $107 \cdot 43$ & 3.71 & 76.00 & 34.57 & $9 \cdot 00$ & $2 \cdot 71$ & 214 & 867 & $\mathbf{M}$ \\
\hline 16 & 10 & $4 \cdot 90$ & $36 \cdot 10$ & $5 \cdot 60$ & $60 \cdot 90$ & $22 \cdot 30$ & $45 \cdot 80$ & $1 \cdot 60$ & 935 & 0 & - \\
\hline 17 & 10 & $4 \cdot 10$ & $62 \cdot 60$ & $2 \cdot 90$ & $62 \cdot 60$ & $12 \cdot 00$ & $7 \cdot 40$ & $1 \cdot 80$ & 418 & 752 & $\mathrm{H}$ \\
\hline 18 & 10 & $3 \cdot 80$ & $31 \cdot 70$ & $5 \cdot 20$ & $40 \cdot 00$ & $18 \cdot 40$ & $43 \cdot 70$ & $1 \cdot 10$ & 865 & 0 & 一 \\
\hline 19 & 10 & $1 \cdot 10$ & $95 \cdot 80$ & $3 \cdot 20$ & $73 \cdot 70$ & $23 \cdot 30$ & $9 \cdot 60$ & $2 \cdot 30$ & 133 & 886 & $\mathbf{M}$ \\
\hline 20 & 10 & $1 \cdot 10$ & $112 \cdot 80$ & $4 \cdot 20$ & $82 \cdot 30$ & $24 \cdot 40$ & $12 \cdot 30$ & $2 \cdot 70$ & 246 & 899 & $\mathbf{M}$ \\
\hline 21 & 10 & $1 \cdot 10$ & $104 \cdot 70$ & $3 \cdot 80$ & $76 \cdot 10$ & $24 \cdot 10$ & $9 \cdot 90$ & $2 \cdot 60$ & 173 & 890 & $\mathbf{M}$ \\
\hline 22 & 9 & $5 \cdot 67$ & $47 \cdot 33$ & $2 \cdot 11$ & $12 \cdot 00$ & $3 \cdot 89$ & $9 \cdot 00$ & $1 \cdot 11$ & 865 & 741 & $\mathbf{H}$ \\
\hline 23 & 10 & $1 \cdot 20$ & $104 \cdot 80$ & 3.90 & $78 \cdot 30$ & $20 \cdot 30$ & $10 \cdot 20$ & $2 \cdot 70$ & 203 & 895 & $\mathbf{M}$ \\
\hline 24 & 10 & $1 \cdot 10$ & $113 \cdot 40$ & $3 \cdot 50$ & $78 \cdot 40$ & $21 \cdot 70$ & $10 \cdot 50$ & $2 \cdot 50$ & 167 & 917 & $\mathbf{M}$ \\
\hline 25 & 6 & $4 \cdot 17$ & $28 \cdot 00$ & 3.83 & $29 \cdot 17$ & $16 \cdot 67$ & $12 \cdot 67$ & $1 \cdot 17$ & 622 & 0 & $\bar{\pi}$ \\
\hline 26 & 10 & $4 \cdot 60$ & $51 \cdot 10$ & $3 \cdot 40$ & $62 \cdot 50$ & $34 \cdot 30$ & $16 \cdot 20$ & $1 \cdot 10$ & 587 & 431 & $\mathrm{H}$ \\
\hline 27 & 10 & $4 \cdot 60$ & $35 \cdot 40$ & $3 \cdot 10$ & $53 \cdot 00$ & $65 \cdot 20$ & $18 \cdot 20$ & $1 \cdot 10$ & 738 & 463 & $\mathrm{H}$ \\
\hline 28 & 10 & $4 \cdot 80$ & $25 \cdot 20$ & $2 \cdot 80$ & $54 \cdot 20$ & $6 \cdot 20$ & $16 \cdot 80$ & $1 \cdot 10$ & 596 & 400 & $\mathrm{H}$ \\
\hline 29 & 10 & $3 \cdot 10$ & $33 \cdot 30$ & $2 \cdot 80$ & 63.80 & $26 \cdot 10$ & $25 \cdot 20$ & $1 \cdot 10$ & 527 & 477 & $\mathrm{H}$ \\
\hline (45) & 2 & $5 \cdot 50$ & $37 \cdot 00$ & $2 \cdot 50$ & $30 \cdot 00$ & 0.50 & $4 \cdot 00$ & $1 \cdot 10$ & - & - & $(\mathrm{H})$ \\
\hline 30 & 10 & $4 \cdot 00$ & $42 \cdot 80$ & $5 \cdot 30$ & $45 \cdot 40$ & $36 \cdot 60$ & $49 \cdot 00$ & $1 \cdot 30$ & 917 & 0 & - \\
\hline 31 & 9 & $1 \cdot 11$ & 119.89 & $4 \cdot 11$ & $78 \cdot 78$ & $21 \cdot 78$ & $9 \cdot 89$ & $2 \cdot 67$ & 202 & 946 & M \\
\hline 32 & 10 & $3 \cdot 10$ & $59 \cdot 00$ & $3 \cdot 90$ & $60 \cdot 00$ & $24 \cdot 90$ & $19 \cdot 50$ & $1 \cdot 80$ & 479 & 741 & $\mathrm{H}$ \\
\hline 33 & 10 & $2 \cdot 70$ & $55 \cdot 00$ & $3 \cdot 80$ & $53 \cdot 20$ & $27 \cdot 80$ & $11 \cdot 80$ & $1 \cdot 10$ & 434 & 744 & $\mathrm{H}$ \\
\hline 34 & 10 & $1 \cdot 10$ & $114 \cdot 00$ & 3.90 & $77 \cdot 30$ & $21 \cdot 20$ & $10 \cdot 50$ & $2 \cdot 80$ & 181 & 939 & M \\
\hline 35 & 10 & $3 \cdot 70$ & $66 \cdot 90$ & $4 \cdot 10$ & $52 \cdot 60$ & $25 \cdot 50$ & $12 \cdot 30$ & $1 \cdot 40$ & 477 & 719 & $\mathrm{H}$ \\
\hline 36 & 10 & $1 \cdot 10$ & $116 \cdot 30$ & $3 \cdot 70$ & $79 \cdot 30$ & $22 \cdot 60$ & $9 \cdot 70$ & $2 \cdot 80$ & 201 & 961 & $\mathbf{M}$ \\
\hline 37 & 10 & $2 \cdot 80$ & $70 \cdot 70$ & $4 \cdot 10$ & $55 \cdot 40$ & $27 \cdot 20$ & $14 \cdot 30$ & $1 \cdot 70$ & 435 & 775 & $\mathrm{H}$ \\
\hline 38 & 10 & $1 \cdot 10$ & $123 \cdot 10$ & $4 \cdot 10$ & $81 \cdot 20$ & $26 \cdot 10$ & 11.80 & $2 \cdot 80$ & 232 & 943 & $\mathbf{M}$ \\
\hline 39 & 10 & $1 \cdot 10$ & 123.00 & $4 \cdot 10$ & $78 \cdot 50$ & $19 \cdot 80$ & $10 \cdot 60$ & $2 \cdot 70$ & 198 & 947 & $\mathbf{M}$ \\
\hline 40 & 10 & $4 \cdot 40$ & $38 \cdot 00$ & $4 \cdot 40$ & $42 \cdot 70$ & $24 \cdot 20$ & $41 \cdot 50$ & $1 \cdot 10$ & 805 & 0 & - \\
\hline 41 & 10 & $1 \cdot 10$ & $115 \cdot 70$ & $4 \cdot 00$ & $78 \cdot 20$ & $20 \cdot 70$ & 10.90 & $2 \cdot 80$ & 192 & 847 & $\mathbf{M}$ \\
\hline 42 & 10 & $3 \cdot 20$ & $47 \cdot 70$ & $4 \cdot 60$ & 34.50 & $23 \cdot 60$ & 13.20 & $1 \cdot 10$ & 560 & 442 & $\mathbf{H}$ \\
\hline 43 & 10 & $1 \cdot 50$ & $96 \cdot 20$ & $3 \cdot 60$ & 69.90 & $16 \cdot 40$ & $10 \cdot 70$ & $2 \cdot 70$ & 137 & 788 & $\mathbf{M}$ \\
\hline 44 & 10 & $2 \cdot 80$ & 55.00 & $4 \cdot 20$ & $38 \cdot 20$ & 14.40 & 13.90 & $1 \cdot 30$ & 463 & 498 & $\mathrm{H}$ \\
\hline
\end{tabular}


program developed at the Scottish Plant Breeding Station. The latter program included a subroutine which gave Euclidean distances between all pairs of clones (Gower and Ross, 1969) based on the sum of squared differences between their means. BMD programmes (Dixon, 1970) were used for principal components in which all data were standardised before analysis, and for calculating correlations. Standard programs were also used for principal co-ordinate analysis (Blackith and Reyment, 1971) and for calculation of Spearman's rank correlation coefficient (Davies, 1971).

\section{Results}

Clone means for each of the seven variates and the number of surviving ramets in each clone are shown in table 1 ; data from all putative hybrids are grouped after their respective pollen parents. Clone 45 was omitted from analyses since eight of the ten ramets died in the course of the field trial.

Normality tests on the data, and on the residuals (calculated by deducting the appropriate clone mean from the score of each ramet), gave similar results. Flag leaf breadth was the only variate with a normal distribution. Results from the residuals are shown in table 2 . Square root, $\log _{10}$, data

TABLE 2

Normality tesis on residuals-fiducial limits for 95 per cent confidence interval

\begin{tabular}{|c|c|c|c|c|}
\hline \multirow[b]{2}{*}{ Variate } & \multicolumn{2}{|c|}{ Skewness } & \multicolumn{2}{|c|}{ Kurtosis } \\
\hline & & & & \\
\hline Ear emergence & 0.424 & $0 \cdot 887$ & $3 \cdot 156$ & $4 \cdot 080$ \\
\hline Flag leaf length & -0.421 & $0 \cdot 042$ & $2 \cdot 227$ & $3 \cdot 152$ \\
\hline Flag leaf breadth & -0.457 & 0.006 & -0.475 & 0.450 \\
\hline Plant height & -0.627 & $-0 \cdot 164$ & $5 \cdot 842$ & $6 \cdot 766$ \\
\hline No. of panicles & 0.383 & $0 \cdot 846$ & $4 \cdot 513$ & $5 \cdot 437$ \\
\hline Plant diameter & $0 \cdot 205$ & $0 \cdot 668$ & $2 \cdot 494$ & 3.419 \\
\hline Spring growth & -0.008 & 0.455 & 0.359 & $1 \cdot 283$ \\
\hline
\end{tabular}

squared and reciprocal transformations were tested. None of these transformations reduced distributions to normality and most increased the degree of skewness and kurtosis. Untransformed data were therefore used in all following analyses.

Clones 15 and 25 had only seven and six ramets surviving respectively. These clones would have yielded singular variance-covariance matrices since seven variates were measured, and hence were omitted from the test for homogeneity of dispersions. Within-clone dispersion matrices from the remaining 42 clones were heterogeneous $\left(\mathrm{X}_{(1148)}^{2}=1928.4 ; P<0.001\right)$.

Correlations between clones and between all 427 ramets are shown in table 3 for the seven variates.

The percentage of total variation taken up on the first three axes of canonical, principal components and principal co-ordinate analyses is shown in table 4. Scatter diagrams show the position of clones along the first three axes of variation for the three analyses (figs. 1 to 6 ). 
TABLE 3

Correlation coefficients between clones, 42 d.f. (top right), and between ramets, 425 d.f. bottom left)

$\begin{array}{crrrrrrr} & \text { EE } & \text { FLL } & \text { FLB } & \text { PH } & \text { No. Pan. } & \text { PD } & \text { SG } \\ \text { EE } & - & -0.896 & 0.064 & -0.797 & 0.008 & 0.570 & -0.876 \\ \text { FLL } & -0.790 & - & -0.039 & 0.855 & -0.024 & -0.557 & 0.965 \\ \text { FLB } & -0.004 & 0.099 & - & 0.007 & 0.167 & 0.650 & 0.001 \\ \text { PH } & -0.717 & 0.815 & 0.027 & - & 0.141 & -0.379 & 0.873 \\ \text { No. Pan. } & -0.044 & -0.014 & 0.101 & 0.130 & - & 0.202 & -0.062 \\ \text { PD } & 0.490 & -0.458 & 0.458 & -0.297 & 0.163 & - & -0.479 \\ \text { SG } & -0.712 & 0.802 & 0.027 & 0.743 & -0.049 & -0.355 & -\end{array}$

$r> \pm 0.298,0.385,0.481, \quad P<0.05,0.01,0.001$ for 42 d.f.

$r> \pm 0.095,0.124,0.158, \quad P<0.05,0.01,0.001$ for 425 d.f.

TABLE 4

Percentage of total variation taken up on first three axes in the three analyses

Form of analysis

Canonical analysis

Principal components analysis

Principal co-ordinates analysis 1st axis

$71 \cdot 88$

$57 \cdot 00$

$64 \cdot 00$ 2nd axis

$12 \cdot 03$

$22 \cdot 00$

$12 \cdot 96$ 3rd axis

$8 \cdot 11$

$13 \cdot 00$

$6 \cdot 35$

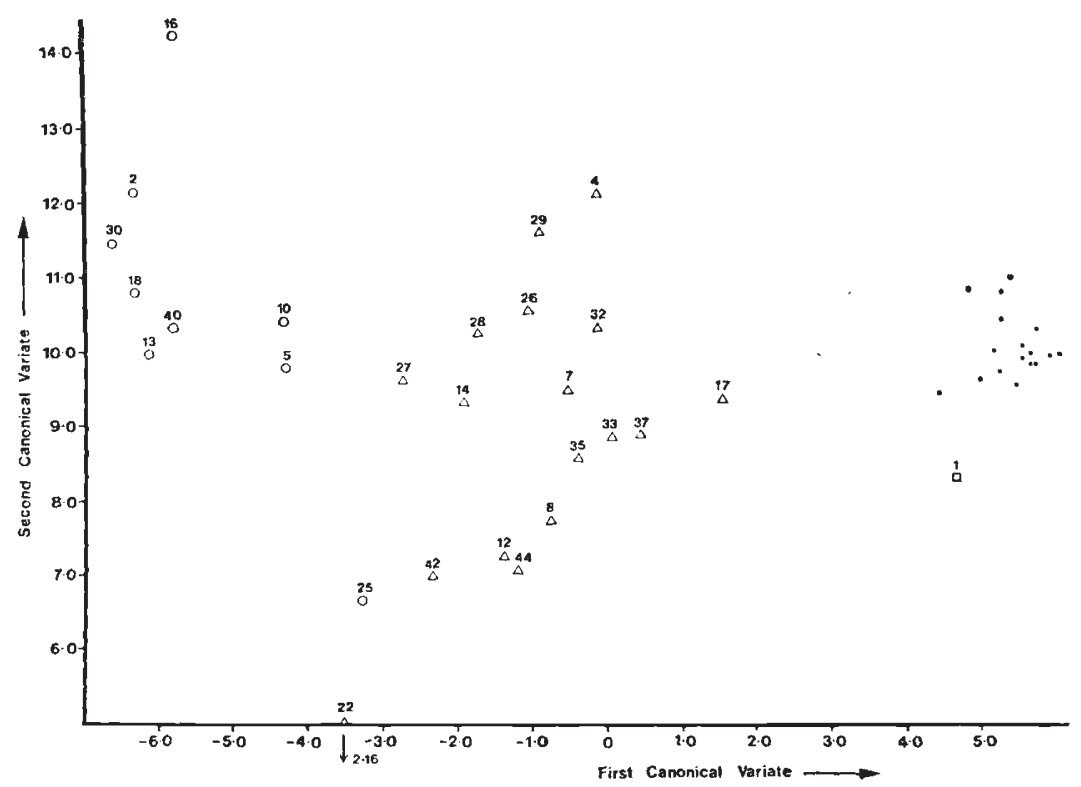

Fig. 1.-Canonical analysis. Clone positions on first and second canonical variates. Square, $P$. ampla; circles, $P$. pratensis clones; triangles, hybrid clones; dots, maternal clones. Diameter of 95 per cent confidence circle for clone with 10 ramets $=I \cdot 24$ units (Seal, 1964). 


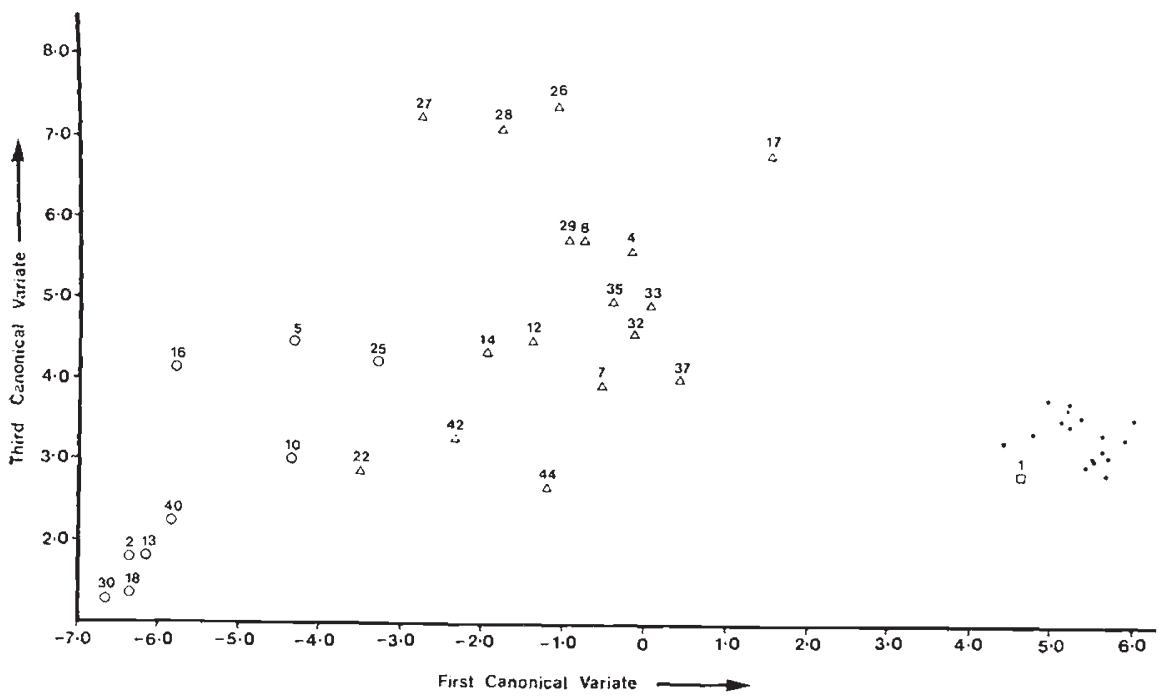

Frg. 2.-Canonical analysis. Clone positions on first and third canonical variates. Square, $P$. ampla; circles, $P$. pratensis clones; triangles, hybrid clones; dots, maternal clones. Diameter of 95 per cent confidence circle for clone with 10 ramets $=1.24$ units.

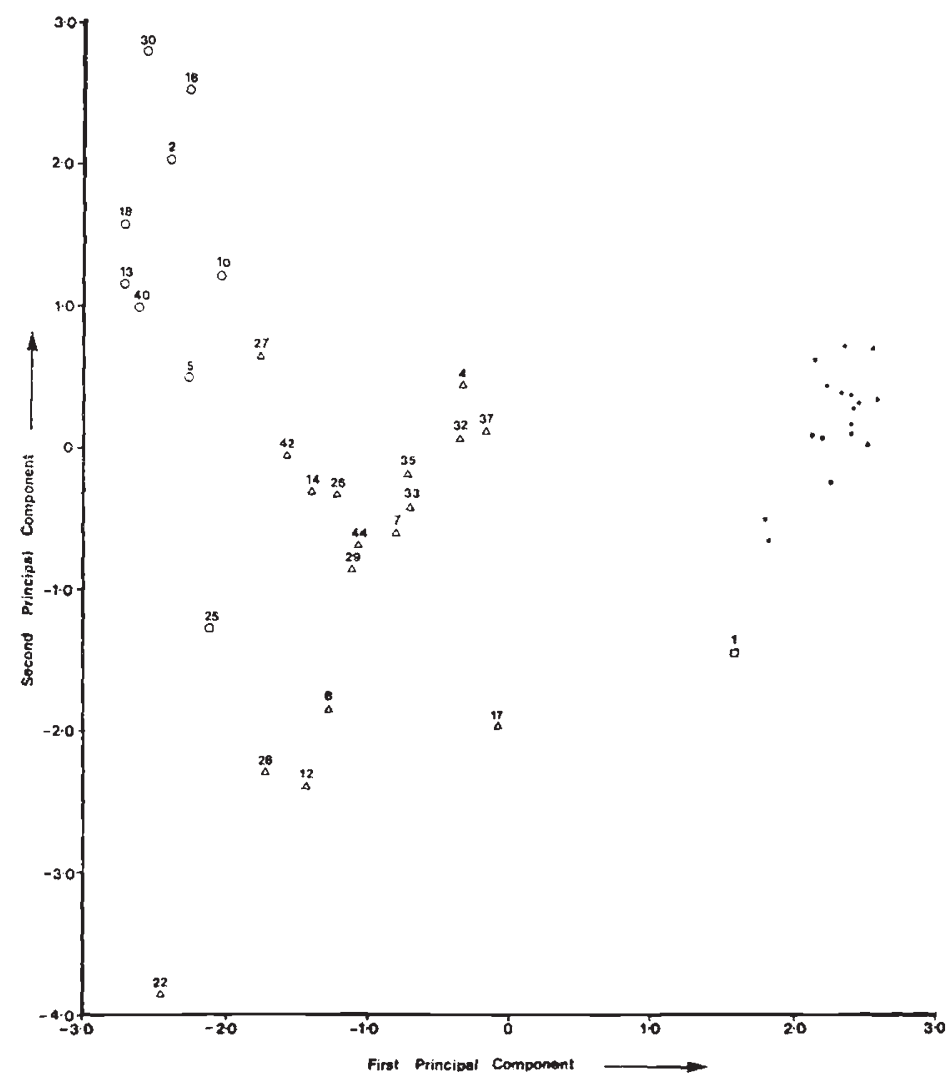

FIG. 3.- Principal components analysis. Clone positions on first and second principal components. Square, $P$. ampla; circles, $P$. pratensis clones; triangles, hybrid clones; dots, maternal clones. 


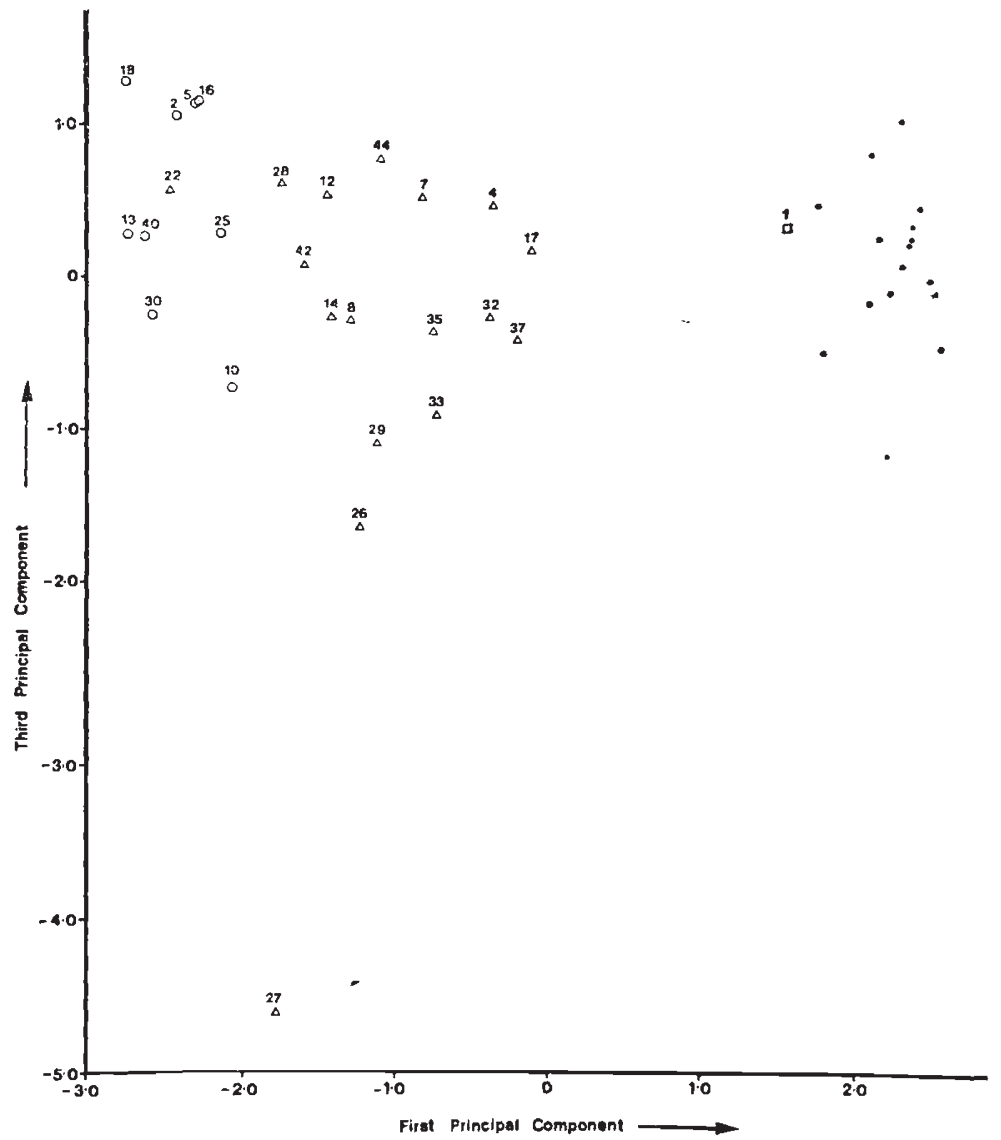

FIG. 4.-Principal components analysis. Clone positions on first and third principal components. Square, $P$. ampla; circles, $P$. pratensis clones; triangles, hybrid clones; dots, maternal clones.

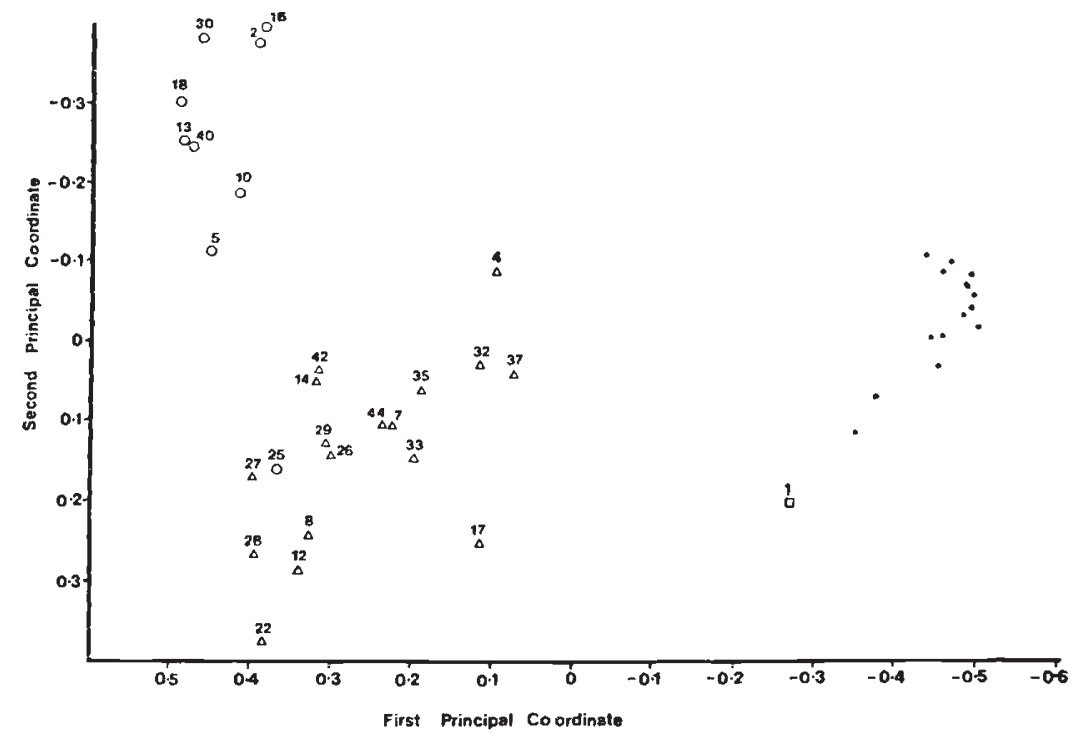

FIG. 5.-Principal co-ordinate analysis. Clone positions on first and second principal co-ordinates. Square, P. ampla; circles, $P$. pratensis clones; triangles, hybrid clones; dots, maternal clones. 


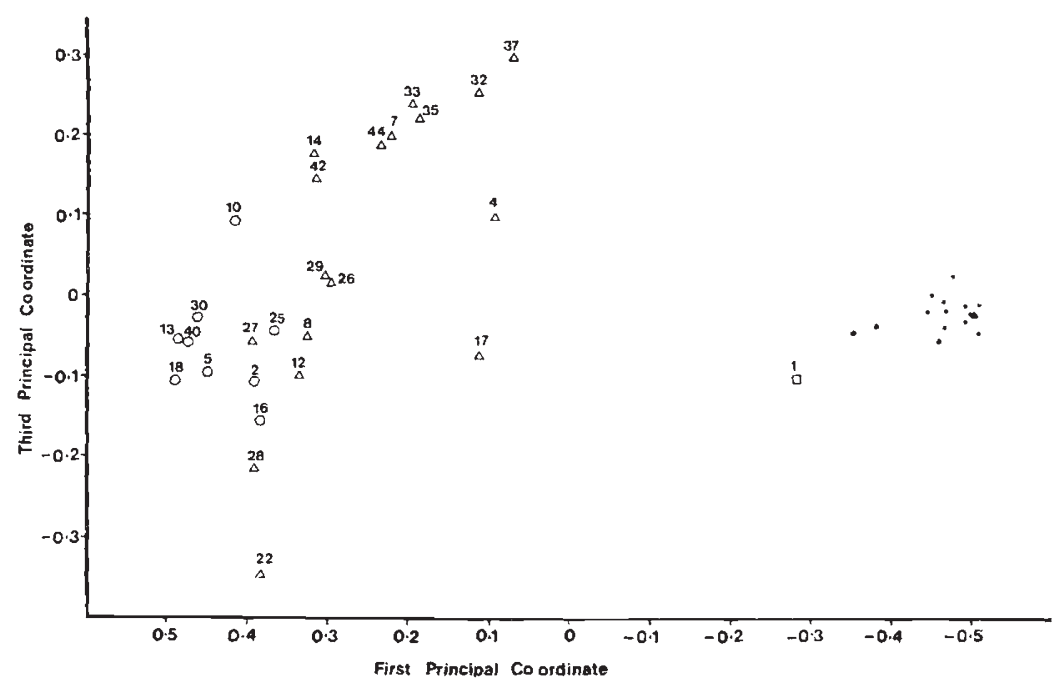

FIG. 6.-Principal co-ordinate analysis. Clone positions on first and third principal co-ordinates. Square, $P$. ampla; circles, $P$. pratensis clones; triangles, hybrid clones; dots, maternal clones.

Euclidean distances between each offspring, $P$. ampla and its pollen parent are included in table 1 (columns 10 and 11). Correlation coefficients and Spearman's rank correlation coefficients were calculated for distances between all clones and $P$. ampla, and the clone positions on the first axis of variation from the three analyses. Similarly, correlations were calculated between the clone positions for each of the first three axes of variation (table 5).

\section{Table 5}

Correlations and rank correlations between clone positions on first axes of variation and generalised distances $(d)$ between $P$. ampla and other 43 clones; and between first three axes of variation from canonical variates, principal components and principal co-ordinates analyses

$r$

Spearman's $r$

$$
\begin{gathered}
d v . \text { Ist canonical } \\
\text { variate } \\
0.9648 * * * \\
0.8905 * * *
\end{gathered}
$$

Canonical variate $v$. principal component principal co-ordinate component $0.9344 * * *$ $0.8755 * * *$
Canonical variate $v$. te
$d v$. lst principal co-ordinate $0.9022 * * *$
$0.8625 * * *$

1 st axis Spearman's $r$ $0.9848 * * *$
$0.9887 * * *$ $0.9648 * * *$ $0.9762 * * *$

Principal component $v$. principal co-ordinate

2nd axis Spearman's $r$

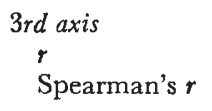


A visual assessment which had been made on plants in the field confirmed that all the clones which clustered near $P$. ampla in figures 1 to 6 were morphologically similar to the seed parent. On the basis of the multivariate analyses it was possible to distinguish between these maternal offspring and those hybrids which exhibited many $P$. ampla characteristics. Progeny tests (Williamson, 1976) have further confirmed the validity of the separation of maternals and hybrids as designated in column 12 of table 1.

\section{Discussion}

Multivariate techniques have been used in plant breeding to investigate various aspects of the relationship between inter- and intra-specific hybrids (Sneath, 1976). Blackith and Reyment (1971) suggest that in a study of hybridisation a combination of morphometric and cytogenetic analyses is desirable but that the situation may arise where the morphometric approach may be the only one available. In the work reported here it represented the most practicable and objective method available and used data which were already recorded for agronomic assessment of the material. Recent studies (Spoor and Hay, 1978) indicate that electrophoresis could also be used in this situation.

The plant material was replicated by vegetative cloning so a canonical analysis of discriminance might be expected to give the best separation of clones since correlations between characters are eliminated and the environmental variation is minimised. However it was not possible to meet the requirement that data should be multivariate normally distributed. None of the transformations tested reduced the level of skewness or kurtosis on six of the seven variates. The heterogeneity of dispersion matrices was probably due largely to these non-normal distributions since the test is known to be sensitive to departures from normality (Hope, 1968). This raises the question of how to modify data to fit the requirements for canonical and principal components analyses or, alternatively, whether it is legitimate to use them at all?

There are few reports of the effect of non-normality in data used for multivariate analyses. Goodman (1968) concluded that the effect of transformations designed to eliminate heterogeneity of dispersion matrices was negligible when he examined generalised distances using both transformed and untransformed data. Cooper (1963) found that the assumption of a multivariate normal distribution was not always necessary, and Blackith and Reyment (1971) point out that the collective evidence indicates that multivariate classification is mostly robust and may be used with confidence. Hope (1968) even suggests that the application of the chi-square test for homogeneity of dispersion is not always desirable, and he also comments that discriminant analysis and analysis of dispersion are sufficiently robust to withstand small discrepancies between dispersion matrices.

The close agreement between the positions of the clones in the three analyses (figures 1 to 6 ) and the high rank correlation coefficients (table 5) for the first and second axes showed that any one of these analyses would have enabled maternal clones to be distinguished from hybrid clones. This would seem to substantiate the view that, at least in this type of problem, a clear separation of the different types of clone was possible despite inherent 
limitations of the data, namely, unequal numbers per clone, some restricted scales of measurement and non-normal distributions, and heterogeneous dispersions. The techniques would therefore seem to be sufficiently robust to cope with practical problems in this field.

Distances have been widely used in numerical taxonomy as a measure of disparity between taxa (Sneath and Sokal, 1973). The advantage of distance measures over other multivariate and clustering methods is that all the information concerning a pair of individuals is contained in the one statistic. The high correlations between the distances between each clone and $P$. ampla, and the clone positions along the first axes of variation showed that nearly all the information necessary for separation of hybrid from maternal clones was represented in the first axis for all three analyses.

The close agreement between the clustering of the maternal-type offspring near $P$. ampla in the scatter diagrams and the more subjective visual assessment, together with the remarkably consistent picture obtained from the three analyses indicate that any one of these multivariate methods could be used with confidence to separate hybrids from maternal offspring.

Acknowledgments.-We wish to thank Dr Patricia J. Watson who produced the $\mathrm{F}_{1}$ hybrids described and recorded the data used in this paper.

\section{References}

Åkerberg, E. 1939. Apomictic and sexual seed formation in Poa pratensis. Hereditas, 25, 359-370.

Åkerberg, E. 1942. Cytogenetic studies of Poa pratensis and its hybrid with Poa alpina. Hereditas, $28,1-126$.

ALMGÅRD, G. 1969. Application of isozyme technique in plant identification. Hereditas, $63,444-445$.

Blackith, R. E., AND REyment, R. A. 1971. Multivariate Morphometrics. Academic Press Inc. (London) Ltd., London.

ClAUSEN, J., KECK, D. D., AND HIESEY, W. M. 1944. Experimental taxonomy. Hybridization of Poa. Carnegic Inst. Wash. Year Book, 43, 75-77.

Clausen, J., KECK, D. D., AND hiesey, w. M. 1945. Experimental taxonomy. Poa hybrids. Carnegie Inst. Wash. Year Book, 44, 73-78.

CoOPER, P. w. 1963. Statistical classification with quadratic forms. Biometrika, 50, 439-448. DAVIES, R. G. 1971. Computer Programming in Quantitative Biology. Academic Press, London. DIXoN, w. J. (Ed.). 1970. BMD Biomedical Computer Programs. University of California Press, Los Angeles.

Goodman, M. м. 1968. The races of maize. II. Use of multivariate analysis of variance to measure morphological similarity. Crop Sci., 8, 693-698.

GoWER, J. C. 1966. Some distance properties of latent root and vector methods used in multivariate analysis. Biometrika, 53, 325-338.

GOWER, J. C., AND Ross, G. J. s. 1969. Minimum spanning trees and single linkage cluster analysis. Appl. Statist., 18, 54-64.

Grun, P. 1954. Cytogenetic studies of Poa. I. Chromosome numbers and morphology of interspecific hybrids. Amer. 7. Bot., 41, 671-678.

HOPE, K. 1968. Methods of Multivariate Analysis. University of London Press Ltd., London. KRzANowskI, w. J. 1972. Techniques in multivariate analysis. In The way ahead in plant breeding. Proceedings of the 6th Congress of EUCARPIA, Cambridge, 1971, 147-155.

müntzing, A. 1940. Further studies on apomixis and sexuality in Poa. Hereditas, 26, 115-190.

SEAL, H. 1964. Multivariate Statistical Analysis for Biologists. Methuen and Co. Ltd., London. SNEATH, P. H. A. 1976. Some applications of numerical taxonomy to plant breeding. Z. Pflanzenzüchtg., 76, 19-46.

SNeAth, P. H. A., AND Sokal, R. R. 1973. Numerical Taxonomy. The Principles and Practice of Numerical Classification. W. H. Freeman and Co., San Francisco. 
SOKAL, R. R., AND Rohlf, F. 1969. Biometry. The Principles and Practice of Statistics in Biological Research. W. H. Freeman and Co., San Francisco.

SPECKMAN, G. J., AND VAN DXJK, G. E. 1972. Chromosome number and plant morphology in some ecotypes of Poa pratensis L. Euphytica, 21, 171-180.

sPOOR, W., AND HAY, JESSICA M. 1978. Identification of Poa pratensis lines using electrophoresis of seed extracts. In press.

Williamson, cynthia J. 1976. Problems in the identification and utilisation of interspecific hybrids of Poa in a plant breeding programme. Ph.D. thesis, University of Edinburgh. 